\title{
Transfer of iodine from soil to vegetables by applying exogenous iodine
}

\author{
Chun-Lai Hong ${ }^{1,2}$, Huan-Xin WENG ${ }^{1, *}$, Ya-Chao QIN ${ }^{1}$, Ai-Lan YAN ${ }^{1}$, Ling-Li XIE ${ }^{1}$ \\ ${ }^{1}$ Institute of Environment \& Biogeochemistry, Zhejiang University, Hangzhou 310027, P.R. China \\ ${ }^{2}$ Institute of Jiaxing Agricultural Science, Jiaxing 314016, P.R. China
}

(Accepted 6 May 2008)

\begin{abstract}
Iodine deficiency disorders are one of the commonest preventable human health problems. Producing iodine-enriched crops could be an effective way to reduce their epidemicity in many regions. However, the actual knowledge on this issue is limited mostly to studies involving grain crops and inorganic iodine fertilizers such as $\mathrm{I}^{-}$and $\mathrm{IO}_{3}^{-}$. Moreover, the translocation, transformation and distribution of iodine from soil to plants are not well understood. Here, we studied iodine transfer from soil to vegetables using both inorganic iodine (KI) and organic, seaweed iodine. Greenhouse culture experiments were undertaken to assess the absorption and accumulation of iodine by four vegetables: Chinese cabbage, lettuce, tomato and carrot. We also investigated the dynamic variation of exogenous iodine in soil by applying KI and a composite of seaweed and diatomite. Our results show first that iodine levels in vegetables increase with the increasing addition of iodine. Second, the iodine content in the edible portion ranks as follows: Chinese cabbage (high I) $>$ lettuce $>$ carrot $>$ tomato (low I). The iodine accumulation in the edible portion of the cabbage is thus 2.25 and 4.45 times higher than that of lettuce and carrot, respectively, and 19.67 times higher than that of tomato. In vegetable tissues the iodine distribution is ranked as: root (high I) $>$ leaf $>$ stem $>$ fruit (low I), except for carrot, where the average iodine level in the rhizome is $50 \%$ of the shoot. Third, vegetable growth is inhibited when the added iodine concentration is higher than $50 \mathrm{mg} \mathrm{kg}^{-1}$. The order of tolerance against iodine toxicity is ranked as: carrot (high tolerance) $>$ Chinese cabbage $>$ lettuce $>$ tomato (low tolerance). Fourth, the seaweed composite iodine fertilizer demonstrates more potential of durability than KI. Indeed, when KI is added to the soil at $150 \mathrm{mg} \mathrm{kg}^{-1}$, the biomass of cabbage, lettuce, tomato and carrot decreases by $34.8 \%, 41.3 \%, 46.8 \%$ and $17.9 \%$, respectively. By comparison, the biomass decreases are lower, $16.6 \%, 22.9 \%, 23.4 \%$ and 9.7\%, respectively, when applying the seaweed composite. Fifth, after harvest, the residual iodine in soil fertilized with KI is only $56 \%$ of the initial addition, which is less than that for seaweed composite. This study is of theoretical importance to understand iodine biogeochemistry and its transfer behavior, and also has practical implications for seeking effective alternatives of iodine biofortification to prevent iodine deficiency disorders.
\end{abstract}

exogenous iodine / vegetable / absorption / biofortification / health / iodine deficiency disorder

\section{INTRODUCTION}

Iodine is an essential microelement for human health. Iodine deficiency disorders (IDDs) are believed to be one of the commonest preventable human health problems (Hetzel, 1983). It has been estimated that nearly 1 billion people (notably in developing countries) suffer from iodine deficiency disorders, thought to be caused by the lack of iodine in the diet (Delange, 1998). These diseases include endemic goiter, cretinism and foetal abnormalities, among others (DeLong et al., 1997). The relationship between the geochemistry of iodine in rock, soil, water, the sea and the atmosphere on the incidence of iodine deficiency disorders is one of the most interesting research studies that is now arousing global interest among scientists.

* Corresponding author: gswenghx@zju.edu.cn
Iodine deficiency in China is severe, particularly in western parts of the country. Although the use of iodized salt has been promoted in China nationwide since the early 1980s, iodine deficiency remains a major health problem in remote provinces such as Xinjiang. A survey in 1999 showed that about $23 \%$ of children aged from 8 to 10 had goiter (Wang F.-R. et al., 2000). In these remote regions, iodine intake by the population is inherently low because of low iodine contents in soil and drinking water compared with those in coastal regions of the country. On the other hand, it is difficult to implement the intake of iodized salt in these regions due to culture and diet customs - the ethnic minority people in western China prefer the locally available rock salt free of charge and Chinese cuisine, usually with high-temperature oil, results in iodine volatilization (Zhang et al., 2000). It is therefore suggested that salt fortification with iodine is not enough to eliminate iodine deficiency disorders in most remote regions 
Table I. Physicochemical properties of the soil used in the experiments. CEC: cation exchange capacity.

\begin{tabular}{|c|c|c|c|c|c|c|}
\hline \multirow[t]{2}{*}{ Soil type } & \multirow{2}{*}{$\begin{array}{c}\text { CEC } \\
\left(\mathrm{cmol} \mathrm{kg}^{-1}\right)\end{array}$} & \multirow{2}{*}{$\begin{array}{c}\text { Organic } \\
\text { matter }(\%)\end{array}$} & \multirow{2}{*}{$\mathrm{pH}$} & \multicolumn{3}{|c|}{ Granular composition (\%) } \\
\hline & & & & $2-0.02 \mathrm{~mm}$ & $0.02-0.002 \mathrm{~mm}$ & $<0.002 \mathrm{~mm}$ \\
\hline Inceptisol & 19.28 & 4.09 & 5.91 & 17.68 & 45.46 & 36.86 \\
\hline $\begin{array}{l}\text { Total I } \\
\left(\mathrm{mg} \mathrm{kg}^{-1}\right)\end{array}$ & $\begin{array}{c}\text { Total N } \\
(\%)\end{array}$ & $\begin{array}{c}\text { Total P } \\
(\%)\end{array}$ & $\begin{array}{c}\text { Total K } \\
(\%)\end{array}$ & $\begin{array}{c}\text { Available N } \\
\left(\mathrm{mg} \mathrm{kg}^{-1}\right)\end{array}$ & $\begin{array}{c}\text { Available P } \\
\left(\mathrm{mg} \mathrm{kg}^{-1}\right)\end{array}$ & $\begin{array}{c}\text { Available K } \\
\left(\mathrm{mg} \mathrm{kg}^{-1}\right)\end{array}$ \\
\hline 2.02 & 0.256 & 0.0704 & 1.68 & 134.6 & 29.5 & 186.4 \\
\hline
\end{tabular}

in China and other effective approaches for iodine fortification via food chains deserve attention.

Generally, about $80 \%$ of people's iodine comes from plant food. Some studies indicate that organic iodine from plant food can keep the diet balanced in iodine nutrition (e.g., Graham et al., 1999; Welch, 2005). In recent years, great progress has been made using agricultural biofortification to improve human micronutrition such as Fe, $\mathrm{Zn}$ and Se, etc. (Graham et al., 1999; Poletti et al., 2004). Although it is established that it is a useful approach to promote iodine levels in agricultural products by applying exogenous iodine to soil (Weng et al., 2003; Zhu et al., 2003; Dai et al., 2004), most of these studies cultivated grain crops and adopted inorganic iodine (e.g., $\mathrm{I}^{-}, \mathrm{IO}_{3}^{-}$) as the exogenous iodine fertilizer (Ashmore et al., 1996; Gregorio, 2000). Mackowiak and Grossl (1999) concluded that even with cultures of a high iodine concentration $\left(100 \mu \mathrm{mol} \mathrm{L}^{-1}\right)$, the iodine content in grains was not high enough to meet the recommended daily requirement of $150 \mu \mathrm{g}$ I (Ziegler and Filer, 1996). Vegetables are basic necessities of life, with large consumption. Although research has shown that vegetables have higher ability than grain crops to accumulate iodine, the translocation, transformation and distribution of iodine from soil to different vegetables are not well understood.

In this study, the uptake of iodine from soil and the accumulation in the edible portion as well as its biological effects were investigated through cultivating four vegetables: Chinese cabbage, lettuce, tomato and carrot. Experimental results provide theoretical and technical evidence for identifying efficient plant species as target crops for iodine supplementation. This study is of theoretical importance to understand iodine biogeochemistry and its transfer behavior, and also has practical implications for seeking effective alternatives of iodine biofortification to prevent iodine deficiency disorders.

\section{MATERIALS AND METHODS}

\subsection{Preparation of iodine fertilizers}

Two exogenous iodine fertilizers were applied in this study. One is seaweed composite iodine fertilizer and the other is KI (analytical grade) fertilizer as a comparison. The seaweed composite iodine fertilizer was composed of seaweed and diatomite. Iodine content in dry seaweed normally ranges from $2-3 \%$, most of which is water-soluble (Hou et al., 1998). Diatomite consists mainly of diatomaceous remains as well as a small quantity of clay minerals. Since diatomite has a strong
Table II. Chemical composition of Hoagland-type nutrient solution.

\begin{tabular}{lccc}
\hline Macronutrient & $\begin{array}{c}\text { Concentration } \\
(\mathrm{mM})\end{array}$ & Micronutrient & $\begin{array}{c}\text { Concentration } \\
(\mu \mathrm{M})\end{array}$ \\
\hline $\mathrm{KNO}_{3}$ & 6.00 & $\mathrm{H}_{3} \mathrm{BO}_{3}$ & 10.0 \\
$\mathrm{Ca}\left(\mathrm{NO}_{3}\right)_{2}$ & 3.50 & $\mathrm{MnSO}_{4} \cdot \mathrm{H}_{2} \mathrm{O}$ & 0.50 \\
$\mathrm{KH}_{2} \mathrm{PO}_{4}$ & 1.33 & $\mathrm{ZnSO}_{4} \cdot 7 \mathrm{H}_{2} \mathrm{O}$ & 0.50 \\
$\mathrm{MgSO}_{4} \cdot 7 \mathrm{H}_{2} \mathrm{O}$ & 0.50 & $\mathrm{CuSO}_{4} \cdot 5 \mathrm{H}_{2} \mathrm{O}$ & 0.20 \\
$\mathrm{NaCl}$ & 0.48 & $\left(\mathrm{NH}_{4}\right)_{6} \mathrm{Mo}_{7} \mathrm{O}_{24}$ & 0.01 \\
& & Fe-EDTA & 200 \\
\hline
\end{tabular}

capacity of adsorption, it leads to slow release of iodine, in favor of its uptake by plants, and maintains soil moisture.

The seaweed composite iodine fertilizer was made as follows. Fresh seaweed was dried at $40{ }^{\circ} \mathrm{C}$. It was then crushed into small granules in a diameter range from 1 to $6 \mathrm{~mm}$ and sieved through a 15 mesh sieve. Diatomite collected from Shenzhen, southern China, was sieved through a 100 mesh sieve. The grained seaweed and diatomite powder were fully mixed in the ratio of 1:1 and then granulated for use (Weng and Cai, 1998). The iodine content in the fertilizer was measured.

\subsection{Materials and vegetable culture}

The soil used in the experiments is classified as an inceptisol, which was developed from a fluvio-aquatic soil matrix. It was collected from the old vegetable production area of Jiaxing, Zhejiang Province of China. The soil was sieved through a $3 \mathrm{~mm}$ mesh sieve and its main agrochemical properties are listed in Table I. Four vegetable species were cultivated: Chinese cabbage (B. Chinesis L.), lettuce (A. Graveolens L. var. dulce DC), tomato (Capsicum annuum L.) and carrot (Raphanus sativus L.).

Pot-culture experiments were conducted in a greenhouse. $3 \mathrm{~kg}$ of soil were bled with iodine fertilizer to obtain different iodine contents of $10,25,50,100$ and $150 \mathrm{mg} \mathrm{kg}^{-1}$, respectively. The soil had a background iodine level of $2.02 \mathrm{mg} \mathrm{kg}^{-1}$. Vegetables planted without iodine fertilizers were used as control groups for comparison. The base fertilizer was applied and the soil moisture was maintained at $50 \%$ of the maximum field water capacity. The fertilized soil was put in a flowerpot. During the experimental period, deionized water was added at regular intervals to keep the moisture stable.

Seeds of Chinese cabbage, lettuce and tomato were germinated on wet filters for two days in the dark at $25^{\circ} \mathrm{C}$ after sterilization. The germinated seeds were then transplanted into quartz sand and were grown on a modified Hoagland-type nutrient solution (Tab. II) to establish seedlings. The seedlings 
with a uniform growth state were transplanted into flowerpots after being grown for 21 days. The sterilized carrot seeds were directly sown in pot soil. Each treatment was performed in triplicate. The growth period of the vegetables was about 3 months. The first cutting grew from March 15th to June 20th and the second cutting from September 20th to January 3rd of the next year. After harvest, vegetable tissues of the root, stem, leaf and fruit were respectively collected. They were rinsed with deionized water and dried with absorbent paper. All of them were measured for their fresh weights and then cut into small pieces. Each type of plant tissue was dried at $50{ }^{\circ} \mathrm{C}$ and subsequently ground with a stainless steel mill. After being sieved through a 60-mesh sieve, the tissue samples were homogenized and stored at $4{ }^{\circ} \mathrm{C}$ until analysis.

\subsection{Chemical analysis}

Total iodine in soil was measured using the method reported by Wang J.-F. et al. (1999). $2.00 \mathrm{~g}$ of sieved soil sample were placed in a silver crucible with $2.5 \mathrm{~mL}$ of $10 \mathrm{M} \mathrm{KOH}$. The mixture was homogenized and dried at $105{ }^{\circ} \mathrm{C}$ for $0.5 \mathrm{~h}$. It was then burnt at $680{ }^{\circ} \mathrm{C}$ for $2 \mathrm{~h}$ until it turned gray. After cooling, the residue was transferred to a $100 \mathrm{~mL}$ volumetric flask using $10 \mathrm{~mL}$ deionized water. The crucible was rinsed with $10 \mathrm{~mL}$ of $1: 2(\mathrm{v} / \mathrm{v}) \mathrm{H}_{3} \mathrm{PO}_{4}$ solution 3 times and again rinsed with deionized water 3 times. All of the rinse solutions were also collected in the volumetric flask. After diluting to $100 \mathrm{~mL}$, the solution was centrifuged. The supernatant was removed with a pipette and then the iodine concentration was measured in duplicate.

Water-soluble iodine was measured using the method of Dai et al. (2006). The soil sample was leached using deionized water at $25{ }^{\circ} \mathrm{C}$ for $90 \mathrm{~min}$ with constant agitation, keeping the ratio of soil versus water at 1:5. After filtering, iodine concentration in the leachate was measured in duplicate.

For iodine concentration in vegetable tissues, 0.5000 $1.0000 \mathrm{~g}$ of tissue subsample weighed with a precision of $0.0001 \mathrm{~g}$ was mixed in a nickel crucible with $\mathrm{K}_{2} \mathrm{CO}_{3}$ and $\mathrm{ZnSO}_{4}$, that are reagents used to fix iodine. After incineration of the organic components, iodine was dissociated. The residue in the crucible was ground and filtered several times with hot deionized water. The leachates were collected in a $50 \mathrm{~mL}$ volumetric flask and then diluted to $50 \mathrm{~mL}$. The iodine concentration was measured in duplicate.

Iodine concentration was determined by spectrophotometry using the ferric thiocyanate-nitric acid catalytic kinetic method (NFQSIC, 1992). V mL of prepared solution subsample (if containing $<1.2 \mu \mathrm{g} \mathrm{I}, \mathrm{V} \leqslant 5 \mathrm{~mL}$ ) was placed in a $10 \mathrm{~mL}$ volumetric flask with $(5-\mathrm{V}) \times 0.8 / 5 \mathrm{~mL}$ of $\mathrm{K}_{2} \mathrm{CO}_{3}\left(30 \mathrm{~g} \mathrm{~L}^{-1}\right)$. After it was diluted to $5.0 \mathrm{~mL}$ with deionized water, $0.5 \mathrm{~mL}$ of ferric thiocyanate-sodium nitrite solution was added and mixed thoroughly. Subsequently, $1 \mathrm{~mL}$ of ammonium ferric sulfate-nitric acid solution was added. The mixture solution reacted at room temperature for exactly $20 \mathrm{~min}$. Its absorbance was then determined in a $1 \mathrm{~cm}$ cell against deionized water in a spectrophotometer peaked at $460 \mathrm{~nm}$.
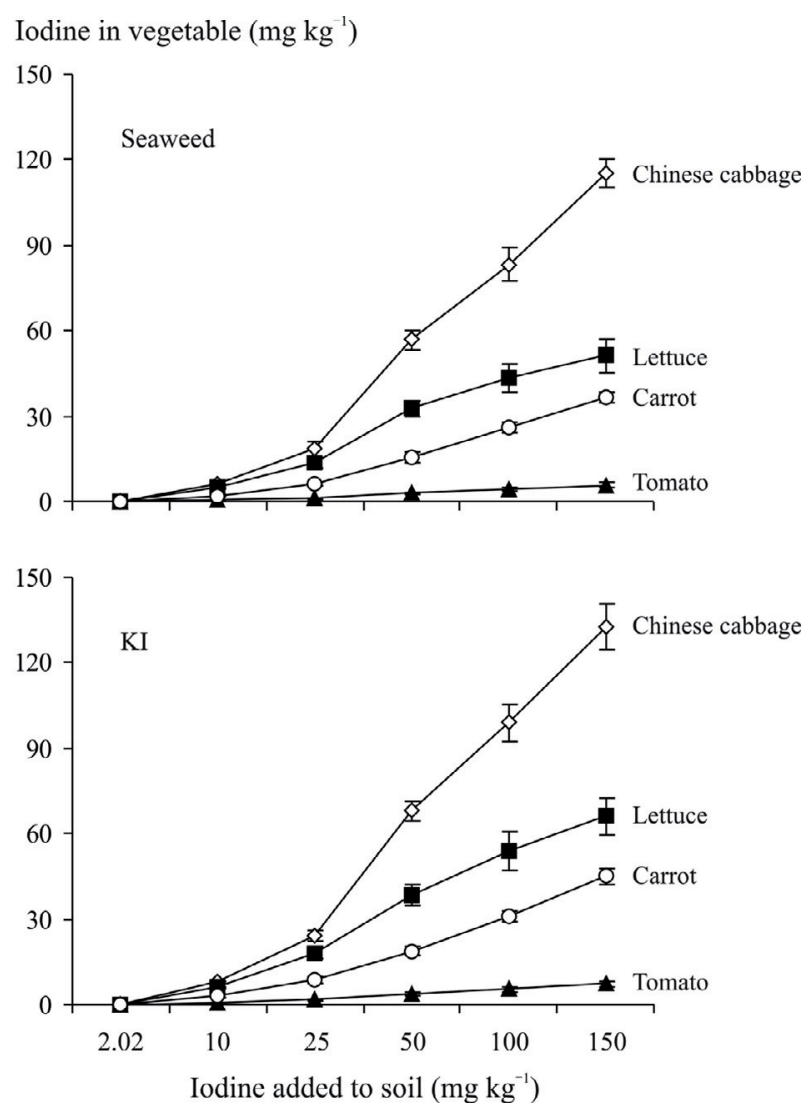

Figure 1. Variation in iodine content in edible portion of vegetables as a function of the additive concentration of exogenous iodine in soil.

Duplicate analyses of each sample with procedural blanks were performed and the mean of the two measurements is reported here. The analytical procedures used for determination of the iodine concentrations had detection limits of 0.04$0.8 \mathrm{mg} \mathrm{I} \mathrm{L}^{-1}$ for soil samples and $0.004-0.24 \mathrm{mg} \mathrm{I} \mathrm{L}^{-1}$ for plant ones. The average recovery during the analysis of plant and soil iodine was $95.4 \%$ and $93.8 \%$, respectively.

\section{RESULTS AND DISCUSSION}

\subsection{Accumulation of iodine in vegetables}

The edible portion of vegetables was determined to compare the effect of two exogenous iodine fertilizers and to evaluate the iodine accumulative ability by different vegetables. Figure 1 illustrates the relation between iodine in the edible portion of different vegetables and the initial additive concentration of exogenous iodine in soil. Iodine accumulation in the edible portion, i.e., cabbage shoots, lettuce stem, tomato fruits and carrot rhizome, directly reflects the capacity of iodine uptake. The iodine content in each vegetable increased with the increasing iodine levels in soil. There was a correlation of iodine between vegetables and soil $(r>0.98 * *)$. Obvious differences in iodine accumulation were observed among the four 

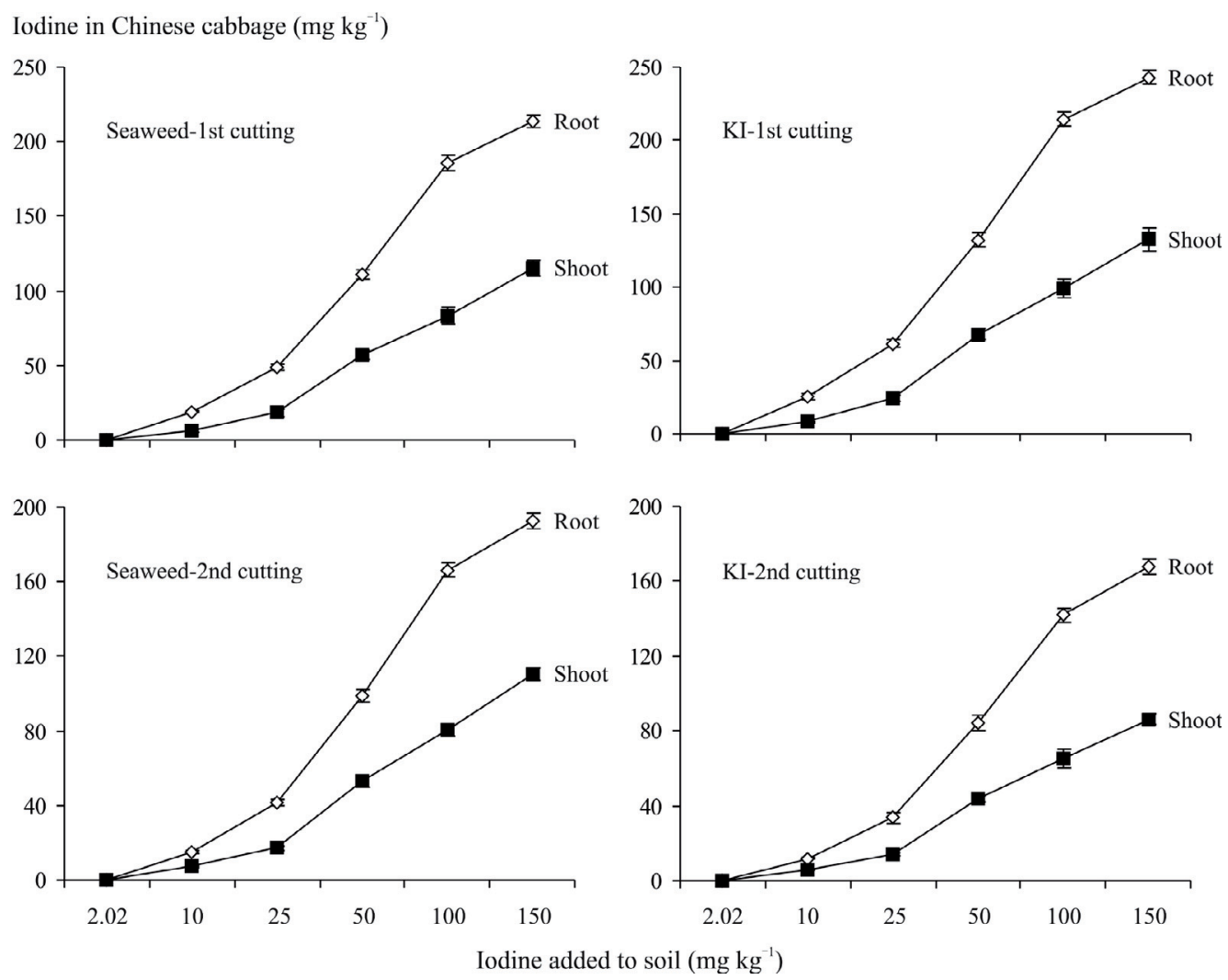

Figure 2. Distribution of iodine in different tissues of Chinese cabbage.

vegetables. The results show that iodine accumulation in the edible portion of the cabbage is 2.25 and 4.45 times higher than those in the lettuce stem and in the carrot rhizome, respectively, and even up to 19.67 times with respect to the tomato fruit. Iodine accumulation in the edible portion of the four vegetable species is ranked as follows: Chinese cabbage $>$ lettuce $>$ carrot $>$ tomato. Consequently, Chinese cabbage and lettuce have priority of selection as iodine enrichment crops.

Figures 2-5 exhibit iodine distribution in different tissues of the four vegetables as a function of the initial iodine addition in soil. Increasing trends were observed in different tissues as the initial iodine levels in soil rose. Nevertheless, there were obvious discrepancies in iodine accumulation between shoots and roots among the four species. Chinese cabbage contained higher iodine in both roots and shoots than the corresponding tissues of lettuce, tomato and carrot. Although iodine contents in both shoots and roots increased simultaneously with increasing iodine supply, iodine in roots rose more sharply than in shoots. Iodine was mainly accumulated in the roots with respect to cabbage, lettuce and tomato, and only a small portion of absorbed iodine was transported to the shoots, especially in the tomato fruit, where the iodine content was less than $5 \%$ as high as that in the root. By contrast, iodine content in the carrot rhizome was less than that in its shoot. These iodine distributions were in agreement with the reports by other authors (e.g., Weng et al., 2003; Zhu et al., 2003; Dai et al., 2004).
The form of iodine fertilized also results in different bioaccumulation of iodine. More iodine was absorbed by applying KI than seaweed composite in the first cutting, whereas in the second cutting there was an opposite trend (Figs. 2-5). Such a result implies a difference in the iodine efficiency of these two fertilizers. Iodine in the form of $\mathrm{KI}$ is quickly effective in plants, whereas organic iodine from seaweed composite is slackly effective due to its high affinity for diatomite. By contrast, in the second cutting, available iodine from KI decreased sharply due to vegetable absorption in the first cutting and KI volatilization, whereas soil fertilized with the seaweed composite maintained relatively high levels of iodine, supplying relatively more iodine for vegetable utilization. The experiments demonstrate that the seaweed composite iodine fertilizer is favorable for iodine accumulation by vegetables due to its long-term efficacy.

\subsection{Effects of exogenous iodine on the growth of vegetables}

According to the pot-culture experiments, the seedlings of the four vegetables were injured when the initial iodine addition in soil was higher than $50 \mathrm{mg} \mathrm{kg}^{-1}$, resulting in chlorosis in young leaves, brown, stunted and coralloid roots, and inhibition in vegetable growth. At the exogenous iodine level of $10 \mathrm{mg} \mathrm{kg}^{-1}$, the biomass of the four vegetables increased 
Iodine in lettuce $\left(\mathrm{mg} \mathrm{kg}^{-1}\right)$
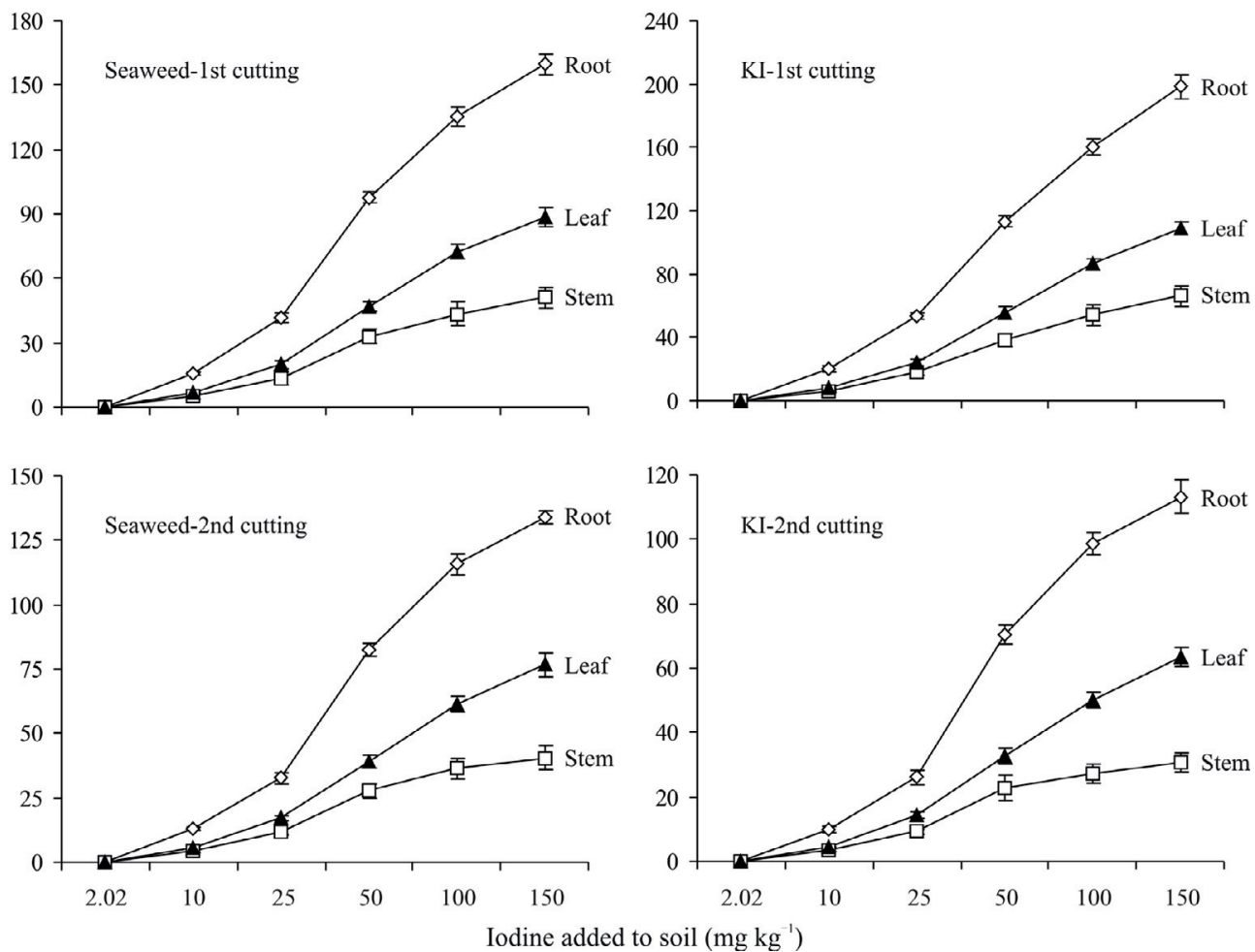

Figure 3. Distribution of iodine in different tissues of lettuce.
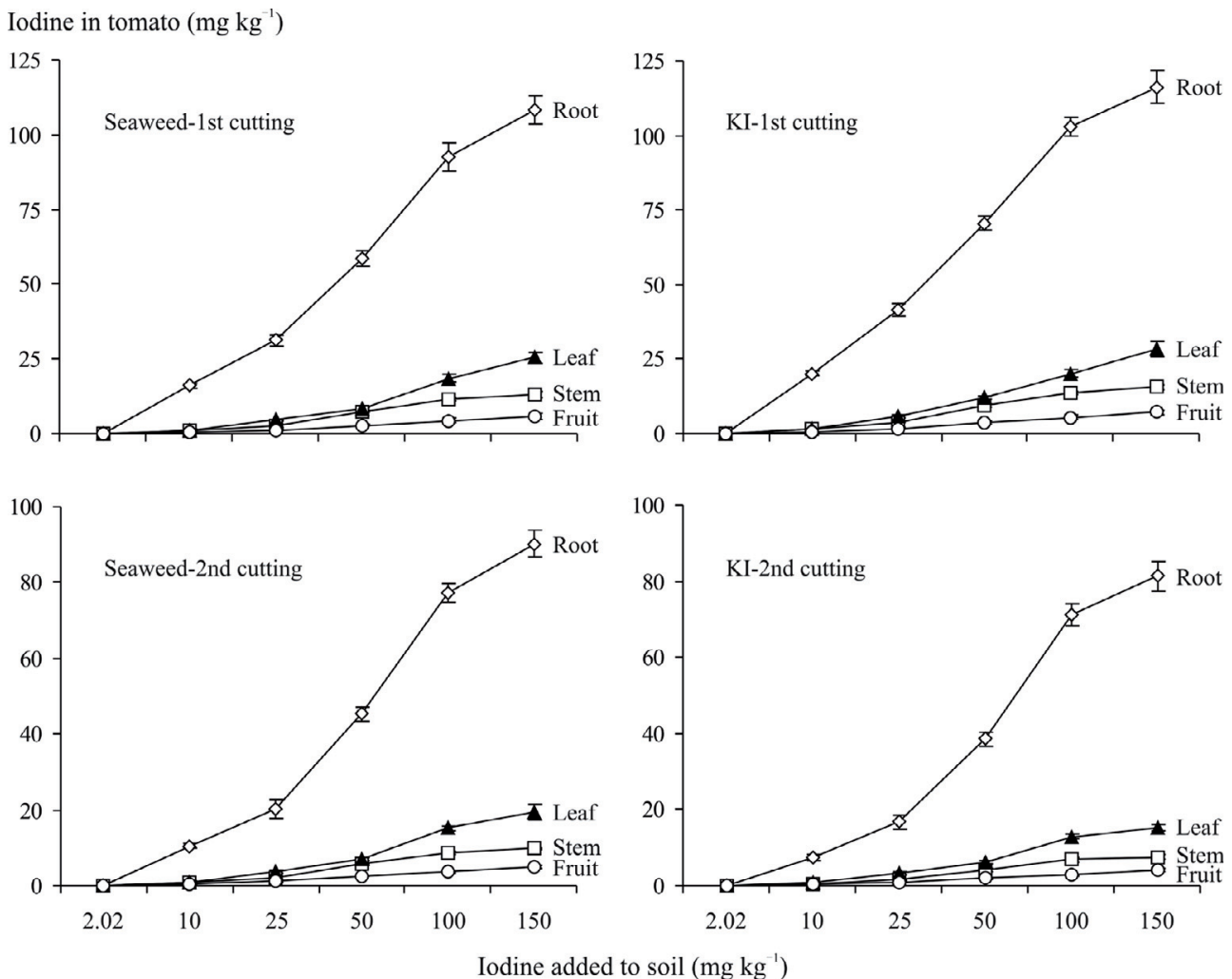

Figure 4. Distribution of iodine in different tissues of tomato. 

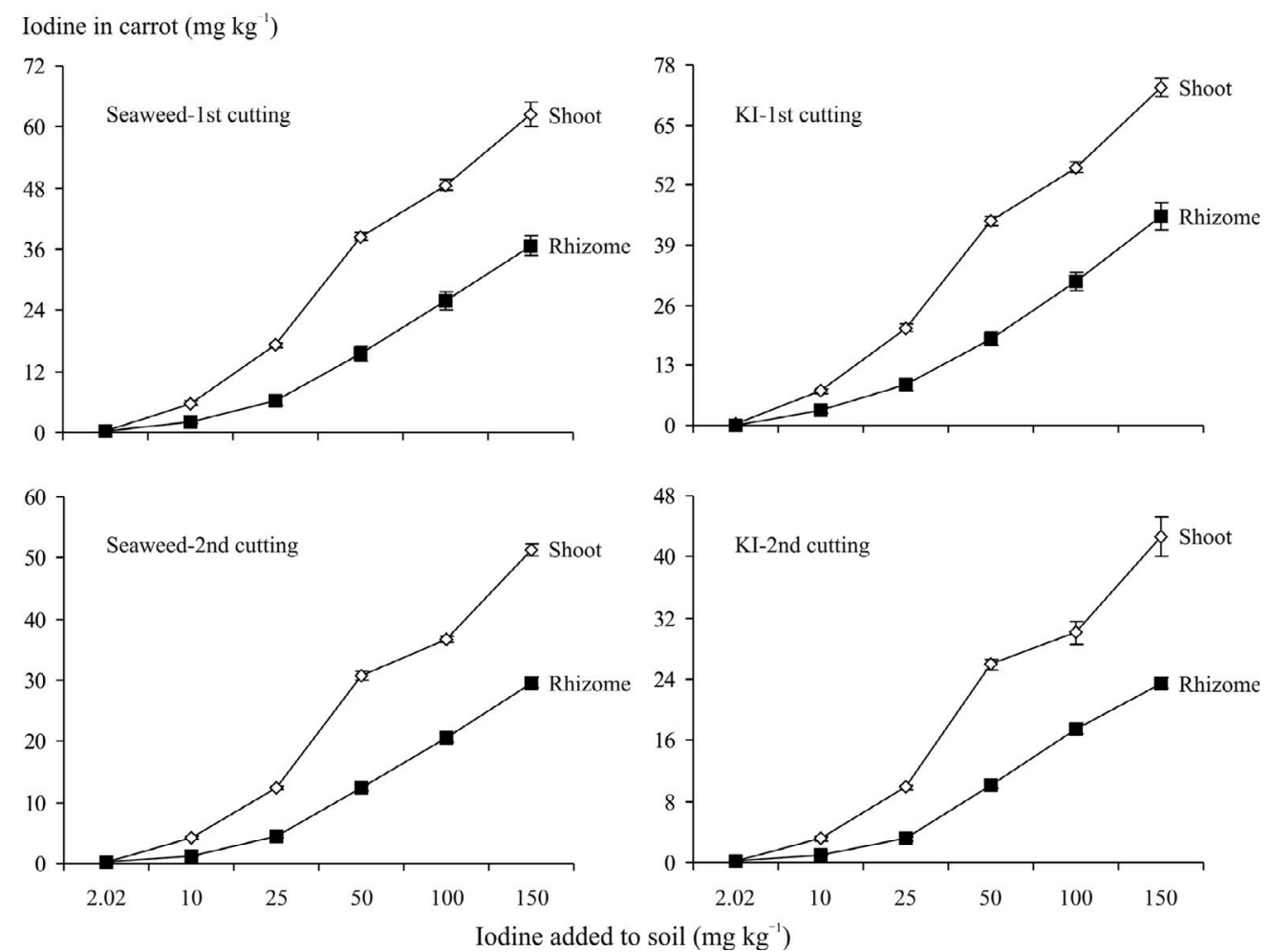

Figure 5. Distribution of iodine in different tissues of carrot.

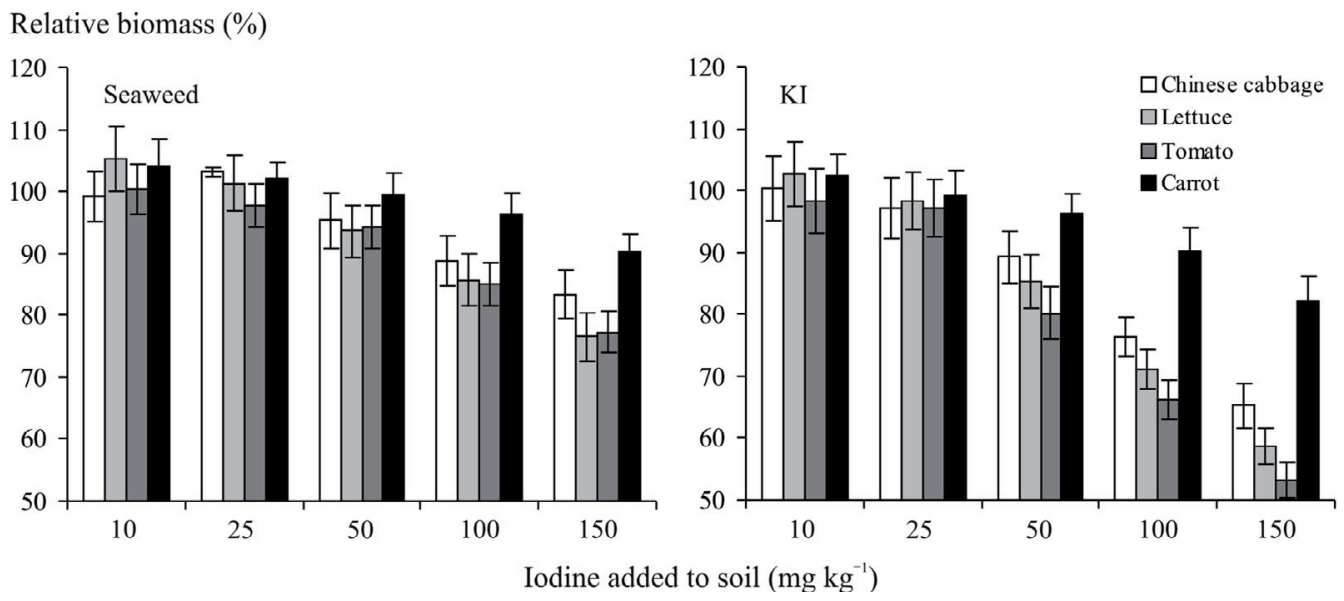

Figure 6. Relative variation in vegetable biomass at different soil iodine levels as compared with those cultivated without iodine fertilizers.

somewhat compared with the control group cultivated without additive iodine (Fig. 6), indicating promotion in vegetable growth. However, when exogenous iodine was higher than $25 \mathrm{mg} \mathrm{kg}^{-1}$, vegetable biomass decreased with the increase in exogenous iodine levels. There were significant negative correlations between biomass yield and initial iodine addition, the correlation coefficients ranging from $-0.93 * *$ to $-0.99 * *$. If the threshold of iodine toxicity in soil was set at $10 \%$ reduction of fresh biomass, they were 96.2, 76.5, 71.3 and $164.9 \mathrm{mg} \mathrm{kg}^{-1}$, respectively, for Chinese cabbage, lettuce, tomato and carrot in terms of the seaweed composite iodine fertilizer. The order of their tolerance to iodine toxicity is ranked as follows: carrot $>$ Chinese cabbage $>$ lettuce $>$ tomato (Fig. 7). The experiments indicate that the seedling of tomato was the most sensitive to excessive iodine, while carrot was the most tolerant to iodine toxicity. These results are consistent with the report of Huang et al. (2003) that excessive iodine is poisonous to plants and different plants exhibit different sensitivities to iodine toxicity.

The four vegetables also exhibit obvious differences in toxic tolerance with respect to these two iodine fertilizers (Fig. 6). In the first cutting, at the initial iodine concentration 
Iodine threshold $\left(\mathrm{mg} \mathrm{kg}^{-1}\right)$

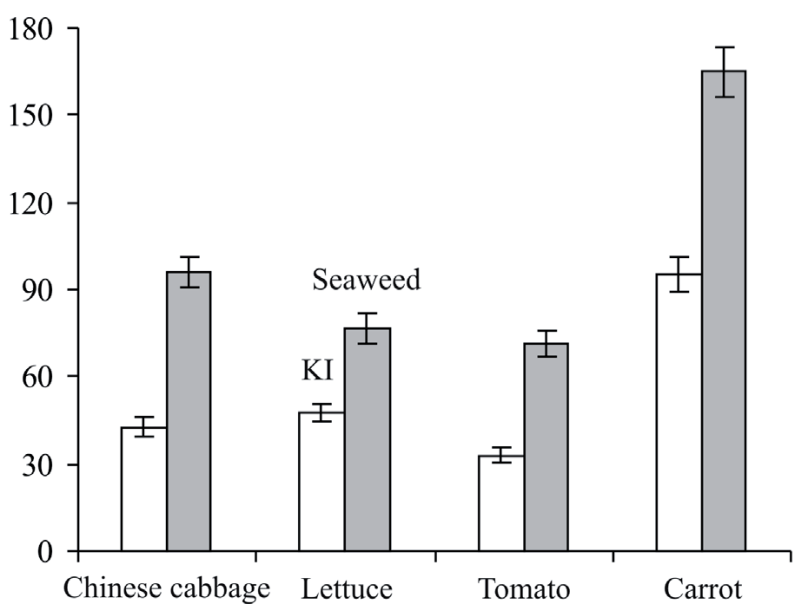

Figure 7. Toxic thresholds of soil iodine for the four vegetables.

of $150 \mathrm{mg} \mathrm{kg}^{-1}$ in the form of KI the biomasses of cabbage, lettuce, tomato and carrot decreased by $34.8 \%, 41.3 \%, 46.8 \%$ and $17.9 \%$, respectively, compared with the control groups cultivated without exogenous iodine addition, whereas after applying seaweed composite, the biomass of these vegetables correspondingly decreased by $16.6 \%, 22.9 \%, 23.4 \%$ and $9.7 \%$ compared with the control groups. In the second cutting, the toxicity of KI decreased clearly and there was no evident difference in biomass reduction after applying these two iodine fertilizers. These results suggest that the seaweed composite iodine fertilizer is prior to selection for cultivation of high iodine vegetables and the iodine release can be well regulated to inhibit iodine toxicity to vegetables.

\subsection{Dynamics of exogenous iodine in soil}

Figure 8 and Table III illustrate the dynamic variations in residual iodine in soil after different cultivation of vegetables. The residual iodine in soil decreased as culture time continued, but the decreasing rate was different between these two iodine fertilizers. The residual iodine from KI was much less than that from seaweed composite - the residual iodine decreased to $56 \%$ of the initial iodine addition after the first cutting was harvested and even to $41.5 \%$ after the second cutting. By contrast, the residual iodine from seaweed composite remained at relatively high levels from $69.0 \%$ down to $56.1 \%$ after the second cutting, confirming its long-term efficacy for iodine supply.

Cultivation of vegetables expedited iodine consumption, which was also different in terms of vegetable species. The maximum loss occurred after cultivation of lettuce, and the next were cabbage and tomato: carrot exerted a little effect on the iodine loss. The reason may be attributed to the discrepancy in the absorption capacity of iodine by vegetables and in a rhizospheric effect on its transfer.
Water-soluble iodine from soil was determined to evaluate the iodine availability in soil (Dai et al., 2006). The dynamic variations in water-soluble iodine are listed in Table IV. It can be seen that water-soluble iodine increased with the increase in the initial iodine concentration in soil, and its content after the second cutting was apparently less than that after the first cutting. The dissolved rate of iodine, which is defined as the ratio of water-soluble iodine to total iodine in soil, was used to evaluate the dissolution ability of iodine from soil. Applying KI fertilizer generally resulted in a higher dissolved rate of iodine as compared with seaweed composite, and in an obvious difference between the first and the second cutting. By contrast, there was no apparent difference between the first and the second cutting after applying seaweed composite. Such results suggest that the available iodine from seaweed composite maintained relative stability during the two cuttings due to the affinity of diatomite for iodine.

Vegetable planting also promoted the dissolved rate of iodine from soil. Among the four vegetables the maximum dissolved rate occurred during lettuce planting, which is consistent with the maximum loss of iodine in soil. The root system of lettuce is very flourishing. The rhizospheric effect activated the immobile iodine, leading to its strengthened availability, and it also expedited iodine loss via soil biochemistry. These results imply an intimate relation of iodine loss and its availability and also suggest the effect of plant species on iodine loss and its activation.

\section{CONCLUSION}

The edible portion of vegetables can absorb and accumulate iodine when exogenous iodine fertilizer is applied. An obvious discrepancy is observed in iodine absorption by vegetables after applying the exogenous iodine fertilizers of KI and seaweed composite. More iodine from $\mathrm{KI}$ is absorbed by vegetables than that from seaweed composite in the first cutting, whereas in the second cutting the trend is the opposite. Favorable iodine addition can accelerate vegetable growth, but excessive iodine is toxic to them. Iodine toxicity in the form of $\mathrm{KI}$ is obviously higher than that in the form of seaweed iodine with respect to the vegetables in the first cutting. The decreased rates of residual and available iodine after applying KI fertilizer are apparently faster than those with seaweed composite. Iodine release from seaweed composite maintains relative stability during the whole culture period, demonstrating a long-term efficacy. Based on the results of the pot-culture experiments and the analyses stated, it is concluded that during the practical applications of iodine biofortification to prevent iodine deficiency disorders, Chinese cabbage and lettuce have priority of selection as a complementary strategy to supplement dietary iodine intake, and the seaweed composite iodine fertilizer is recommended due to its advantages in low toxicity and a long-term efficacy as well as a relatively low cost.

Acknowledgements: This work was financially supported by the National Natural Science Foundation of China (Grant No. 40373043). 
Table III. Data of residual iodine in soil under different planting conditions $\left(\mathrm{mg} \mathrm{kg}^{-1}\right)$.

\begin{tabular}{|c|c|c|c|c|c|c|c|c|c|c|c|c|}
\hline \multirow{2}{*}{ Fertilizer } & \multirow{2}{*}{ Harvest time } & \multirow{2}{*}{$\begin{array}{l}\text { Initial iodine } \\
\text { in soil }\end{array}$} & \multicolumn{2}{|c|}{ Cabbage } & \multicolumn{2}{|c|}{ Lettuce } & \multicolumn{2}{|c|}{ Tomato } & \multicolumn{2}{|c|}{ Carrot } & \multicolumn{2}{|c|}{ No planting } \\
\hline & & & residual & $\%$ & residual & $\%$ & residual & $\%$ & residual & $\%$ & residual & $\%$ \\
\hline \multirow{12}{*}{ KI } & \multirow{5}{*}{1 st cutting } & 2.02 & 1.97 & 97.5 & 1.98 & 98.0 & 1.96 & 97.0 & 1.97 & 97.5 & 2.01 & 99.5 \\
\hline & & 10 & 7.1 & 71.0 & 6.9 & 69.0 & 7.2 & 72.0 & 7.4 & 74.0 & 7.5 & 75.0 \\
\hline & & 25 & 18.1 & 72.4 & 17.2 & 68.8 & 18.6 & 74.4 & 18.7 & 74.8 & 19.3 & 77.2 \\
\hline & & 50 & 34.1 & 68.2 & 33.5 & 67.0 & 35.3 & 70.6 & 34.8 & 69.6 & 35.7 & 71.4 \\
\hline & & 100 & 65.2 & 65.2 & 59.6 & 59.6 & 72.1 & 72.1 & 75.6 & 75.6 & 76.2 & 76.2 \\
\hline & \multirow{7}{*}{ 2nd cutting } & 150 & 90.3 & 60.2 & 85.8 & 57.2 & 96.6 & 64.4 & 98.3 & 65.5 & 105.5 & 70.3 \\
\hline & & 2.02 & 1.96 & 97.0 & 1.95 & 96.5 & 1.98 & 98.0 & 1.99 & 98.5 & 2.21 & 99.5 \\
\hline & & 10 & 5.7 & 57.0 & 5.5 & 55.0 & 5.9 & 59.0 & 6.1 & 61.0 & 6.6 & 66.0 \\
\hline & & 25 & 13.6 & 54.4 & 12.8 & 51.2 & 14.5 & 58.0 & 15.6 & 62.4 & 16.7 & 66.8 \\
\hline & & 50 & 25.8 & 51.6 & 24.5 & 49.0 & 27.6 & 55.2 & 28.4 & 56.8 & 31.3 & 62.6 \\
\hline & & 100 & 48.8 & 48.8 & 45.1 & 45.1 & 53.8 & 53.8 & 56.3 & 56.3 & 66.2 & 66.2 \\
\hline & & 150 & 70.2 & 46.8 & 65.3 & 43.5 & 78.4 & 52.3 & 81.8 & 54.5 & 90.5 & 60.3 \\
\hline \multirow{12}{*}{ Seaweed } & \multirow{5}{*}{ 1st cutting } & 2.02 & 1.95 & 96.5 & 1.94 & 96.0 & 1.95 & 96.5 & 1.99 & 98.5 & 2.2 & 99.9 \\
\hline & & 10 & 7.9 & 79.0 & 7.6 & 76.0 & 8.1 & 81.0 & 8.2 & 82.0 & 8.5 & 85.0 \\
\hline & & 25 & 19.6 & 78.4 & 18.1 & 72.4 & 19.8 & 79.2 & 20.2 & 80.8 & 20.2 & 80.8 \\
\hline & & 50 & 38.6 & 77.2 & 35.8 & 71.6 & 39.9 & 79.8 & 40.7 & 81.4 & 41.3 & 82.6 \\
\hline & & 100 & 75.2 & 75.2 & 70.3 & 70.3 & 78.7 & 78.7 & 81.8 & 81.8 & 84.3 & 84.3 \\
\hline & \multirow{7}{*}{ 2nd cutting } & 150 & 109.4 & 72.9 & 100.9 & 67.3 & 115.3 & 76.8 & 118.4 & 78.9 & 124.3 & 82.9 \\
\hline & & 2.02 & 1.95 & 96.5 & 1.98 & 98.0 & 2.03 & 98.6 & 2.03 & 99.4 & 2.2 & 99.9 \\
\hline & & 10 & 6.7 & 67.0 & 6.5 & 65.0 & 7.2 & 72.0 & 7.3 & 73.0 & 7.3 & 73.0 \\
\hline & & 25 & 16.6 & 66.4 & 15.7 & 62.8 & 17.6 & 70.4 & 17.9 & 71.6 & 18.2 & 72.8 \\
\hline & & 50 & 30.3 & 60.6 & 29.6 & 59.2 & 33.1 & 66.2 & 34.2 & 68.4 & 35.8 & 71.6 \\
\hline & & 100 & 64.6 & 64.6 & 59.9 & 59.9 & 70.3 & 70.3 & 71.4 & 71.4 & 72.1 & 72.1 \\
\hline & & 150 & 91.2 & 60.8 & 86.4 & 57.6 & 95.6 & 63.7 & 97.8 & 65.2 & 103.2 & 68.8 \\
\hline
\end{tabular}

Residual iodine $\left(\mathrm{mg} \mathrm{kg}^{-1}\right)$
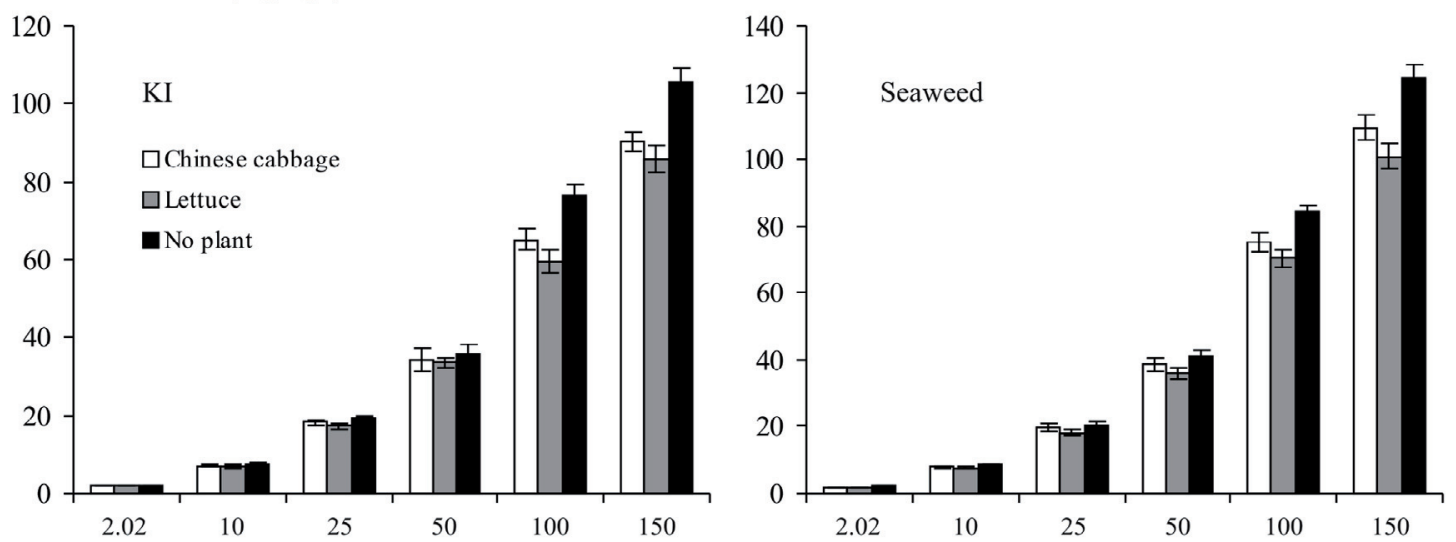

Iodine added to soil $\left(\mathrm{mg} \mathrm{kg}^{-1}\right)$

Figure 8. Variation in residual iodine in soil under different planting conditions. 
Table IV. Dynamic variations in water-soluble iodine in soil with different vegetable planting $\left(\mathrm{mg} \mathrm{kg}^{-1}\right)$.

\begin{tabular}{|c|c|c|c|c|c|c|c|c|c|c|c|c|}
\hline \multirow{2}{*}{ Fertilizer } & \multirow{2}{*}{ Harvest time } & \multirow{2}{*}{$\begin{array}{l}\text { Initial iodine } \\
\text { in soil }\end{array}$} & \multicolumn{2}{|c|}{ Cabbage } & \multicolumn{2}{|c|}{ Lettuce } & \multicolumn{2}{|c|}{ Tomato } & \multicolumn{2}{|c|}{ Carrot } & \multicolumn{2}{|c|}{ No planting } \\
\hline & & & content & $\%$ & content & $\%$ & content & $\%$ & content & $\%$ & content & $\%$ \\
\hline \multirow{8}{*}{$\mathrm{KI}$} & \multirow{4}{*}{1 st cutting } & 10 & 0.227 & 3.2 & 0.234 & 3.4 & 0.230 & 3.2 & 0.229 & 3.1 & 0.232 & 3.1 \\
\hline & & 50 & 1.841 & 5.4 & 1.943 & 5.8 & 1.800 & 5.1 & 1.705 & 4.9 & 1.606 & 4.5 \\
\hline & & 100 & 4.498 & 6.9 & 4.410 & 7.4 & 4.686 & 6.5 & 4.384 & 5.8 & 4.267 & 5.6 \\
\hline & & 150 & 7.675 & 8.5 & 7.893 & 9.2 & 7.631 & 7.9 & 7.077 & 7.2 & 7.174 & 6.8 \\
\hline & \multirow{4}{*}{ 2nd cutting } & 25 & 0.489 & 3.6 & 0.524 & 4.1 & 0.478 & 3.3 & 0.514 & 3.3 & 0.568 & 3.4 \\
\hline & & 50 & 1.109 & 4.3 & 1.176 & 4.8 & 1.131 & 4.1 & 1.079 & 3.8 & 1.221 & 3.9 \\
\hline & & 100 & 2.537 & 5.2 & 2.615 & 5.8 & 2.636 & 4.9 & 2.589 & 4.6 & 3.111 & 4.7 \\
\hline & & 150 & 4.352 & 6.2 & 4.440 & 6.8 & 4.625 & 5.9 & 4.499 & 5.5 & 5.068 & 5.6 \\
\hline \multirow{7}{*}{ Seaweed } & \multirow{2}{*}{1 st cutting } & 10 & 0.268 & 3.4 & 0.266 & 3.5 & 0.267 & 3.3 & 0.262 & 3.2 & 0.255 & 3.0 \\
\hline & & 150 & 7.111 & 6.5 & 7.264 & 7.2 & 6.918 & 6.0 & 6.867 & 5.8 & 6.588 & 5.3 \\
\hline & \multirow{5}{*}{ 2nd cutting } & 10 & 0.214 & 3.2 & 0.227 & 3.5 & 0.223 & 3.1 & 0.226 & 3.1 & 0.226 & 3.1 \\
\hline & & 25 & 0.581 & 3.5 & 0.596 & 3.8 & 0.598 & 3.4 & 0.590 & 3.3 & 0.582 & 3.2 \\
\hline & & 50 & 1.272 & 4.2 & 1.332 & 4.5 & 1.290 & 3.9 & 1.265 & 3.7 & 1.289 & 3.6 \\
\hline & & 100 & 3.165 & 4.9 & 3.234 & 5.4 & 3.163 & 4.5 & 3.284 & 4.6 & 3.244 & 4.5 \\
\hline & & 150 & 5.289 & 5.8 & 5.356 & 6.2 & 5.162 & 5.4 & 5.183 & 5.3 & 5.263 & 5.1 \\
\hline
\end{tabular}

\section{REFERENCES}

Ashmore C.B., Gwyther J.R., Sims H.E. (1996) Some effects of pH on inorganic iodine volatility in containment, Nucl. Eng. Des. 166 347-355.

Dai J.-L., Zhu Y.-G., Zhang M., Huang Y.-Z. (2004) Selecting iodineenriched vegetables and the residual effect of iodate application to soil, Biol. Trace Elem. Res. 101, 265-276.

Dai J.-L., Zhu Y.-G., Huang Y.-Z. (2006) Availability of iodide and iodate to spinach (Spinacia oleracea L.) in relation to total iodine in soil solution, Plant Soil 289, 301-308.

Delange F. (1998) Risks and benefits of iodine supplementation, Lancet 351, 923-924.

DeLong G.R., Leslie P.W., Wang S.-H., Jiang X.M., Zhang M.L., Rakeman M., Jiang J.Y., Ma T. (1997) Effect on infant mortality of iodination of irrigation water in a severely iodine-deficient area of China, Lancet 350, 771-773.

Graham R.D., Senadhira D., Beebe S., Iglesias C., Monasterio I. (1999) Breeding for micronutrient density in edible portions of staple food crops: conventional approaches, Field Crop. Res. 60, 57-80.

Gregorio G.B., Senadhira D., Htut T., Graham R.D. (2000) Breeding for trace mineral density in rice, Food Nutr. Bull. 21, 382-386.

Hetzel B.S. (1983) The iodine deficiency disorders (IDD) and their eradication, Lancet 2, 1126-1129.

Hou X., Chai C., Qian Q. (1998) Determination of chemical species of iodine in some seaweed, Oceanogr. Literature Rev. 45, 243-244.

Huang Y.-Z., Zhu Y.-G., Hu Y., Liu Y.-X., Dai J.-L. (2003) Iodine in soilplant systems and prevention of iodine deficiency disorders, Ecol. Environ. 12, 228-231 (in Chinese).
Mackowiak C.L., Grossl P.R. (1999) Iodate and iodide effects on iodine uptake and partitioning in rice (Oryza sativa L.) grown in solution culture, Plant Soil 212, 135-143.

National Feedstuff Quality Supervision and Inspection Center (NFQSIC) (1992) Method for the determination of iodine in feedstuffs - Ferric thiocyanate-nitric acid catalytic kinetic method (GB/T 13882-92), Standards Press of China, Beijing (in Chinese).

Poletti S., Gruissem W., Sautter C. (2004) The nutritional fortification of cereals, Curr. Opin. Biotech. 15, 162-165.

Wang F.-R., Ilixat, Ma L., Yang C.-Z., Yerkin, Mèliyam, Palidan, Jiang J.-Y., Hai X., Gülina, Shania, Xu X.-F., Malia (2000) 1999 survey of the iodine deficiency disorders in Xinjiang Province, China, Endemic Diseases Bull. 15, 59-61 (in Chinese).

Wang J.-F., Duan L.-Z., Liu N.-H. (1999) Determination of micro amounts of iodine in soil by amplified reaction colorimetric method, Anal. Laboratory 18, 71-74 (in Chinese).

Welch R.M. (2005) Agriculture: the real nexus for enhancing bioavailable micronutrients in food crops, J. Trace Elem. Med. Bio. 18, 299-307.

Weng H.-X., Cai Q.-X. (1998) A manufacture method of iodine composite fertilizer. Invention Patent in China, Grant No. ZL 94108836.7 (in Chinese).

Weng H.-X., Weng J.-K., Yong W.-B., Sun X.-W. (2003) Capacity and degree of iodine absorbed and enriched by vegetable from soil, J. Environ. Sci. 15, 107-111.

Zhang L.-J., Chen Z.-W., Wang J.-Y., Bao J.-M. (2000) Iodine loss from iodized salt during processing, sale and consumption, Zhejiang J. Preventive Med. 12, 32-34 (in Chinese).

Zhu Y.-G., Huang Y.-Z., Hu Y., Liu Y.-X. (2003) Iodine uptake by spinach (Spinacia oleracea L.) plants grown in solution culture: effects of iodine species and solution concentrations, Environ. Int. 29, 33-37.

Ziegler E.E., Filer Jr. L.J. (1996) (Eds.) Present Knowledge of Nutrition (7th ed.), ILSI Press, Washington DC, pp. 361-365. 